\begin{abstract}
CHEMISTRY: ACADEMY AND BUSINESS VENTURE. Today, more than ever, research and development drives the process of innovation which is central to industrial competitiveness. This is a unique opportunity for academia, industry and government to make the paradigm shift necessary to foster the appearance of a brazilian knowledge intensive chemical industry.
\end{abstract}

Keywords: chemical industry; competitiveness; human resources.

\section{QUÍMICA: ACADEMIA E EMPREENDIMENTO}

Em maior ou menor grau o Brasil e todos os demais países do planeta estão submetidos a tensão da globalização. A exposição das organizações a abertura do mercado tem resultado em situações de ameaça de extinção e/ou oportunidades de crescimento sem precedentes. O estado produtor, incapaz de competir com eficiência, está em rápido processo de extinção. As privatizações estão na ordem do dia. Do lado privado para se alcançar competitividade global a resposta tem sido megafusões ou alianças estratégicas. O mercado global está expondo assim de forma transparente as eficiências e ineficiências de cada país. O mercado seleciona Darwiniamente a eficiência eliminando a incompetência. A grande mobilidade da informação e do capital e a integração transnacional da economia permite antecipar que o único que ficará confinado às fronteiras de cada país, serão as pessoas. Assim, o patrimônio de uma nação é a sua gente com suas competências e capacidades de imaginar o futuro e realizá-lo num ambiente de competição e/ ou colaboração global. Portanto, a função sócio-econômica de uma nação é melhorar continuamente o padrão de vida dos seus cidadãos o que se passa necessariamente pelo incremento de sua participação na economia mundial.

Neste contexto o mais importante é o que fazemos, como fazemos e a velocidade das nossas ações e não o que possuímos. Capital é importante para sustentar a criação de valor, mas o retorno e o risco são infinitamente superiores a qualquer experiência do passado.

É exatamente esta reflexão a que contém o cerne que explica as incertezas que configuram o nosso futuro e o futuro de todas as nações. E é este posicionamento estratégico o que nos permite ambicionar uma postura de líderes e não de caudatários históricos que apenas "acompanham" o que os outros fazem.

Entretanto, esta constatação traz também uma outra reflexão, que é que numa sociedade do conhecimento e de símbolos abstratos a agregação de valor está concentradamente nas mãos dos indivíduos mais educados. Assim, a força centrífuga da globalização tende a formar redes planetárias de agregadores de valor incorporando apenas os indivíduos preparados e as instituições mais avançadas para este novo contexto. Já podemos assistir ao desarraigo de pessoas e organizações dos seus países de origem. É uma má notícia para nós que já somos parte de uma sociedade de profundos contrastes sócio-econômicos. Mas é assunto para reflexão crítica por parte da nossa inteligência que deverá assumir com coragem e determinação uma responsabilidade histórica sem precedentes.

E-mail: microbiologica@openlink.com.br
Estamos convencidos que é neste contexto que devemos avaliar nossa função social seja na Academia, na Indústria ou no Governo.

\section{UMA PREMISSA BÁSICA}

Para participar ativamente da rede global de agregação de valor necessitamos exercitar duas funções simultaneamente: velocidade e foco. Isto significa que há absoluta necessidade de dotar de simultaneidade o processo de agregação de valor resultante da apropriação de um determinado conhecimento. Eis é que surge a questão da necessidade de sintonizar os esforços das comunidades acadêmica e empresarial.

\section{O PROCESSO DE AGREGAÇÃO DE VALOR NUMA ECONOMIA GLOBAL}

Note que o ato de fabricar um determinado produto não significa que esta seja a etapa de maior agregação de valor e de controle do mercado. Pelo contrário, as produções de rotina são feitas onde o trabalho braçal é menos remunerado. Por isso da concentração de centros de pesquisas nos países centrais e de produção nos países mais pobres do planeta. As patentes garantem o monopólio legal do mercado e o marketing global a difusão e uso da nova invenção.

$\mathrm{Na}$ criação de valor há essencialmente três componentes:

1. O observador de necessidades insatisfeitas

2. O resolvedor de problemas

3. O integrador que possibilita o empreendimento

Todos os três componentes podem estar dentro de uma mesma organização. E, de fato, nas grandes corporações de base tecnológica existem os três componentes. Mais recentemente, entretanto, pequenas companhias têm empresariado melhor a evolução de novas idéias e conceitos integrando competências independentes. Este é o modelo da empresa virtual.

$\mathrm{Na}$ indústria do conhecimento, os três componentes de agregação de valor são essencialmente formados por analistas de símbolos pois tratam de assuntos abstratos para o homem comum que consome um produto sofisticado em termos de conteúdo simbólico, mas de percepção simples pelo seu uso. Ex. a terapia anti AIDS é baseada em imagens abstratas de biologia molecular, química, medicina etc., mas a sua aplicação é de fácil percepção: ajuda a tratar a infecção pelos vírus da AIDS.

$\mathrm{Na}$ medida em que os produtos incorporam novos conceitos e desenhos e resolvem problemas mais específicos, eles se tornam mais valiosos que os produtos de produção rotineira. Portanto, o grupo mais educado (analistas de símbolos) tende a assumir um papel hierárquico superior e crescente na sociedade. 
Novos recursos humanos altamente qualificados (analistas de símbolos abstratos) e novos conhecimentos são tipicamente produtos, mas não exclusivos, da Academia. Portanto, a Academia de qualquer região do mundo deve-se posicionar criticamente quanto as suas funções neste novo paradigma global.

Assim, vemos a relação universidade indústria no contexto maior da busca de uma unidade funcional por meio da integração sinérgica destas duas vertentes essenciais do afazer humano. Como empresários estamos interessados em alcançar uma posição estratégica forte através de ações inovatórias, introduzidas com velocidade. Não vemos mais fronteiras geográficas nem institucionais na busca de soluções para um determinado problema.

Entretanto, temos a obrigação de nos empenhar para disseminar colaborações nacionais que contribuam para viabilizar, em última instância, a melhoria do nível de vida de toda a população brasileira.

\section{OS VALORES NA FORMAÇÃO DE NOVOS RECURSOS HUMANOS}

Se as pessoas passaram a ter uma relevância superior na nova organização, é lógico que seus valores sejam condizentes com a explicitação da sua hierarquia e responsabilidade.

Um especialista em análise de símbolos, um pesquisador por ex., deve estar treinado em quatro habilidades básicas para participar efetivamente na criação de valor: Capacidade de Abstração, Capacidade de Experimentação, Capacidade de Integração e Capacidade Empreendedora.

\section{Capacidade de Abstração}

É fundamental para simplificar a realidade de forma a entende-la e manipulá-la. A abstração é essencialmente uma vertente reducionista da realidade: formamos pessoas especialistas em manipulações e reinterpretações de subsegmentos microscópicos de nossa realidade. Atribuímos o valor do mérito a quem é capaz de manipular conceitos, instrumentos, digerir dados e tecer conclusões sobre um determinado assunto. Aqui surgem valores adicionais, curiosidade, criatividade etc., considerados valores acadêmicos fundamentais. Todo cientista inovador deve procurar continuamente novas formas de representar a realidade. Cada nova representação deve ser mais reveladora e profunda que a anterior.

Nas melhores escolas, os estudantes são treinados a questionar a origem e natureza dos dados que lhes são apresentados. O estudante aprende a analisar o seu objeto de estudo de muitos ângulos e à luz de hipóteses diferentes (aprendizado). Nas piores escolas a ênfase é na transmissão da informação já digerida (ensino). A fonte é o livro texto e não os dados experimentais de um conhecimento continuamente em evolução. Nas boas escolas os alunos adquirem uma visão dinâmica do mundo que incorpora a idéia da mudança como oportunidade.

\section{Capacidade de Experimentação}

Somente é possível perceber novas formas de abstração e de idealizar uma realidade organizada, através da experimentação. Mantemos partes da realidade constantes enquanto variamos outras. Buscamos formas de descrever causas e consequiências. $\mathrm{O}$ estudante de certa forma assume o compromisso de vida de ser responsável pela própria continuação da sua educação. A capacidade de experimentação está assim associada ao conceito de aprender a aprender. A experimentação como base do método científico não está limitada a ciências exatas. Ela é o melhor método de aprendizado evoluído pelo homem.

Em geral o paradigma da atuação universitária é limitado pelos valores analisados até agora. Por isso muitos professores pensam que para resolver um problema é suficiente sentar, pensar e desenvolver uma solução que resolva o problema. Esta é a fantasia que permeia o cérebro de muito pesquisador "competente". A realidade é outra; pois a solução, para ser solução, deve ter o potencial de incorporar-se a um processo produtivo que envolve a integração de muitos outros fatores, normalmente, fora do campo de percepção de um pesquisador. Entretanto, a combinação da capacidade de abstração com a de experimentação conduzem normalmente à "reconhecida" independência intelectual. O corolário é o mérito pelo exercício da liberdade intelectual.

As coisas mudaram. E muito. O cotidiano globalizante, com a busca obsessiva da eficiência e da produtividade através da inovação, e intolerante com a lentidão, fez surgir um valor adicional superior: Interdependência e Colaboração.

$\mathrm{O}$ foco do sucesso mudou do individual (independente) para o sucesso do grupo. Reconhece-se mais importância ao trabalho em equipe pela sinergia e motivação de cérebros independentes que criam em conjunto uma organização superior interdependente.

\section{Capacidade de Integração}

A percepção da realidade como um sistema de causas e conseqüências é um degrau superior da educação. O nosso sistema se satisfaz no nível de abstrações reducionistas, sem desenvolver capacidade de Integração. A grande maioria das nossas escolas universitárias perpetua a compartimentalização na compreensão de nossa realidade. Como se cada uma das partes fosse completamente independente das outras. É um tipo de conveniência didática que não conduz à sabedoria. $\mathrm{O}$ "especialista" assim formado fica alienado na sua diminuta e irrelevante realidade reducionista.

Para descobrir novas oportunidades é essencial a capacidade de ver o conjunto e compreender as relações entre todas as partes da realidade. Por exemplo, um processo poluidor é melhor resolvido na origem: mudando a tecnologia que dá origem à poluição e não tratando os efeitos da poluição! Mas para chegar a essa conclusão é necessário focalizar no problema por inteiro e não no poluente! A compreensão da origem do problema nos dá a possibilidade de atacar seus aspectos básicos: uma oportunidade de desenvolver novo conhecimento com o valor agregado da relevância. Assim, o conceito de relevância incorpora o do mérito. Neste sentido vale lembrar que é mais significativo fazer a pergunta correta, do que encontrar soluções perfeitas para perguntas erradas. A capacidade de integração está relacionada à capacidade de reflexão crítica.

É no trabalho multidisciplinar de grupos de especialistas interdependentes que a nova organização encontra sua máxima expressão de eficiência e competitividade. Simultaneidade é a conseqüência natural na colaboração de grupos interdependentes. Surge aqui novamente a necessidade de relacionar ciência e indústria.

O desenvolvimento de cada uma das qualificações essenciais para o acontecer acadêmico, requer uma postura para aceitar e progredir através das mudanças. Isto é o chamado Espírito Empreendedor que nos conduz à:

\section{Capacidade Empreendedora}

As mudanças criam oportunidades mas podem ser devastadoras se ignoradas ou não antecipadas. Portanto, a melhor situação é ser autor-ator da mudança e não simples espectador. É fácil entender que o espectador paga o preço da sua indolência e submissão.

Portanto, vejo os intelectuais como empreendedores essenciais para a renovação contínua da nossa realidade e a expansão e fortalecimento permanente do tecido de recursos humanos sofisticados formados pelo exercício de abstrações e reinterpretações da realidade. Um intelectual é, portanto, um empreendedor na busca permanente de novas abstrações de causas e conseqüências.

A capacidade empreendedora deve agregar vontade de 
empreender e unir a motivação para gostar do risco do desconhecido como fonte de progresso. A vontade de empreender está relacionada com o incentivo ao empreendimento. A nossa cultura corporativista e isonomista tem criado barreiras mentais e de disposição ao empreendimento. A estabilidade como meio necessário para a criação intelectual e não como conseqüência tem populado os intramuros universitários com muitos indivíduos intelectualmente acomodados que acabaram criando referenciais de valor onde a emoção da relevância é coisa para outros mundos. Indivíduos que buscam modelos inventados por outros para interpretar a nossa realidade, criam uma visão incompleta ou tergiversada deixando de usufruir do manancial de oportunidades de uma realidade diferente.

Por não termos assumido com coragem o risco das nossas próprias existências intelectuais, vivemos paradigmaticamente presos a referências de valor do passado e de outras culturas que, na sua evolução em velocidades sem precedentes, se tornaram dominantes num sentido diferente. Não é mais o poder do dinheiro das grandes organizações ou o poder militar.

É o poder mais legítimo do ser humano: a sua capacidade para reinterpretar a realidade e criar novas formas de cotidiano com freqüência crescente.

\section{A DÉCADA PERDIDA}

A incompreensão desta nova dinâmica determinou o fím do chamado modelo de substituição de importações julgado esgotado e a década de 80 considerada perdida.

Entretanto a causa desse esgotamento nunca foi adequadamente analisada, para tomarmos ações corretivas que sintonizem o País, de forma permanente, com a era de mudanças rápidas que estamos vivendo. $\mathrm{O}$ modelo funcionou enquanto a velocidade das mudanças era pequena e a indústria relativamente moderna e amparada pelo Governo. Mas quando as mudanças se tornaram freqüentes a obsolescência ficou obvia e insustentável. Muitas empresas consideradas exemplos emblemáticos de modernidade sucumbiram a abertura e a globalização.

\section{O NOVO "MODELO"}

A nova estratégia colocada para o desenvolvimento do país está baseada na integração da economia brasileira ao mercado global.

De acordo com esta idéia, a integração irá trazer vários benefícios: 1. redução de preço dos bens importados, disponibilizando alternativas de consumo e baixando o preço dos bens produzidos internamente. 2. Incremento, através da concorrência, das inovações tecnológicas, maior produtividade e diminuição de custos. 3. Integração produtiva das empresas brasileiras a economia global como passo importante para a melhoria do seu padrão tecnológico. Ou seja, sem explicitar, o Governo reconhece a importância da tecnologia, mas no fundo não compreende, como até agora não compreendeu a natureza e alcance da "tal tecnologia".

Tecnologia é a expressão de uma Competência Essencial.

Esta competência é feita de dois componentes: domínio dos aspectos básicos de uma certa disciplina (química dos esteróides por ex) e a facilidade de aplicação desses conhecimentos (anticoncepcionais por ex).

Por isso a ciência não garante o desenvolvimento. É o seu uso e exercício que alavanca o progresso e a modernização da sociedade. Adquire assim seu sentido social mais amplo e se torna compreensível ao homem comum que a incorpora a sua cultura.

\section{O PROGRAMA PADCT}

No meio da década de ' 80 um pequeno número de observadores atentos percebeu que a riqueza contemporânea consistia em criar produtos intensivos em conhecimento e que a velocidade de renovação dos produtos era a base da competitividade e progresso das organizações. Só que a indústria era um compartimento estanque no usufruto de um mercado fechado e a incipiente comunidade acadêmica, fonte do conhecimento e de recursos humanos, outro compartimento. Ambos sem comunicação e sem compreensão adequada do paradigma industrial pós moderno.

A idéia do PADCT era a de resgatar esse problema e incorporar a ciência como fator essencial para a modernização permanente do País.

Levamos mais de doze anos de exercício de PADCT mas ainda não conseguimos efetivar o objetivo central do programa.

O Governo tem falhado em não reconhecer que o desenvolvimento de qualquer Competência Essencial leva tempo e que, portanto, é necessário uma "Política Industrial, Ética e Incentivadora". A omissão explícita do Governo está incorporada na chamada "política de mercado". Segundo esta são as próprias forças do mercado que selecionam as organizações e os produtos que a sociedade legitima. Nem nos Estados Unidos da América do Norte, reconhecido como o "novo império", isto é verdade. Não duvidamos que o mercado seja a maior e mais perfeita alavanca para o desenvolvimento encontrada até agora. Podemos discordar das tensões sociais que ela gera, mas não podemos negar os resultados. Por esta razão para o Brasil se tornar uma sociedade organizada empreendedora, é necessário de uma política adequada à estrutura e antecedentes históricos do País. De outra forma, a globalização poderá se tornar apenas numa miragem modernizadora que desintegre socialmente o Brasil.

Sem explicitar uma política incentivadora de agregação de valor no País, estaremos sendo apenas espectadores e receptáculo da política industrial dos outros países. O efeito da política sustentada na área da química é visível na Petroquímica que é um tipo de empreendimento que no Brasil integrou capital-tecnologia-política. A experiência do PADCT demonstrou que a maioria dos proponentes do lado da indústria estão fortemente concentrados nos centro de pesquisas das petroquímicas. Simplesmente esta é a principal indústria química nacional de peso, adequada a participar do PADCT.

Contraditoriamente, é a indústria que menos precisa e a que menor valor agrega por unidade. Cria uma pequena reserva de mercado para a química de polímeros e catálise, mas não estimula a pequena empresa que busca a grande agregação de valor e que se aproxima da fronteira do conhecimento. Desta forma o programa que era para mudar está apenas perpetuando a situação anterior na academia e na indústria.

No fim do ano passado houve um seminário de avaliação do PADCT II. Foi possível observar a satisfação da comunidade presente com os resultados alcançados. Provavelmente na curta história de química brasileira nunca houve tanta fartura de recursos para os grupos mais poderosos do País. Evidentemente a parte da Academia apoiada pelo programa encontra-o sensacional e quer o status quo. Não percebe, entretanto, do perigo de continuar indiferente a falta de uma indústria de alto nível de ambição que integre seu potencial criativo com as necessidades do mercado.

A Academia pensa que cumpre com a sua obrigação e o programa legitima este sentimento apoiando, principalmente por falta de outros proponentes, projetos essencialmente de mérito acadêmico.

\section{O MOMENTO ATUAL}

A internacionalização da economia brasileira, coloca os três protagonistas principais na gestão do conhecimento - Academia, Indústria e Governo - numa encruzilhada.

A universidade sabe, e está certa, que a sua função mais importante, é o desenvolvimento intelectual através da formação 
de seres humanos automotivados para a criatividade. O Governo tem que aderir a essa função, pois é uma das suas responsabilidades inalienáveis. Por outro lado, uma boa parte da comunidade já entendeu a importância da existência de uma indústria química poderosa como componente essencial no ciclo do conhecimento e de alavancamento sócio-econômico do Brasil. Entretanto, por algumas das razões já analisadas, a indústria, de uma maneira geral, enfrenta o desafio da sua sobrevivência, através de ações de curto prazo e ou com projetos de pouco atrativo para a Universidade.

O problema do PADCT então, é que os seus protagonistas principais têm no presente, poucos elementos de ligação.

Vemos duas alternativas extremas:

\section{Ação do PADCT sem Política Industrial}

Neste caso continuaremos com a tendência atual: a maioria dos pesquisadores insiste em trilhar o caminho do mérito, sem ambições mais amplas, fragilizando seu próprio futuro.

Outra parte, motivada pelo valor da relevância e a interdisciplinaridade busca a integração com grupos de pesquisa e indústrias fora do País. Não faltarão adjetivos ofensivos para estes, mas é alternativa perfeitamente compreensível na perspectiva da globalização.

A parte negativa desta hipótese, é que as conexões internas serão substituídas por outras, que determinarão a região geográfica para a agregação de valor. Não contribuirá tanto para a formação de um tecido forte de apropriação do conhecimento no País, nem ao desenvolvimento das Competências Essenciais em indústrias locais. Acontece assim o desarraigo do País de grupos avançados intelectualmente dando espaço para questionamentos quanto a relevância desses grupos de pesquisa para o Brasil.

\section{Ação do PADCT com Política Industrial}

Neste caso o Governo junto com a comunidade, negocia uma política industrial com compromissos recíprocos. A idéia básica é buscar formas de financiar e capitalizar as relações Ciência-Indústria com uma visão de meio (3 - 4 anos) e longo prazo (7 - 10 anos).

Possivelmente o resgate da situação atual, tenha que passar pelo nascimento de novas empresas de base tecnológica, capazes de compreender os meandros do mundo acadêmico e a problemática industrial e de mercado. Estas empresas poderão desenvolver um caráter integrado ou servir como interfaces apropriadas para clientes já fincados no mercado mas sem intimidade com o processo de agregação de valor.

Sempre com ênfase no produto e não no projeto, o incentivo do Governo poderia ser:

2.1. Tratamento fiscal e de crédito apropriado para empresas nascentes. Inclusive contratos de risco com retorno condicionado ao sucesso.

2.2. Estímulo ao investimento tecnológico por empresas de médio e grande porte com demanda tecnológica mas não atendidas pela legislação vigente que somente privilegia, empresas com receitas taxáveis elevadas (Petroquímicas por ex).
2.3. Estímulo a estruturação de um sistema de "venture capital" capaz de entender a importância do processo de agregação de valor desde a base até a comercialização. Esta é uma forma de incentivar a mudança do caráter imediatista e de aversão ao risco pela confiança no longo prazo e no poder alavancador do conhecimento.

2.4. Poder de Compra do Estado privilegiando as empresas que estejam efetivamente engajadas em programas integrados de desenvolvimento tecnológico competitivo. Isto é particularmente importante agora que a lei de patentes está em vigência.

2.5. Reconhecimento específico para os cientistas participantes de uma determinada invenção como forma de premiação e reconhecimento e estímulo adicional para a relevância.

O estabelecimento de uma política industrial que incentive o resultado tenderá a criar um novo cenário nas relações entre os atores-autores que determinarão a competitividade da química brasileira em um mundo globalizado.

A indicação do PADCT como programa central de mobilização é natural. É transparente na sua gestão e legitimado pela própria comunidade. É uma experiência única no mundo que poderá servir de modelo para outros países que, como o nosso, se ressentem do imediatismo e espírito de colonizador temporário com que têm sido conduzidos.

\section{A ESCOLHA DE ÁREAS PARA A INTEGRAÇÃO CIÊNCIA-INDUSTRIA}

Explicamos anteriormente que o desenvolvimento de uma Competência Essencial é um dos fatores fundamentais para a sobrevivência e progresso na indústria. Um dos componentes é o domínio dos princípio básicos de uma determinada disciplina.

É exatamente esta qualificação que permitirá a certos grupos da Universidade a interagir com a Indústria ou dar origem as novas empresas de base tecnológica. Por exemplo, um grupo especialista em ecologia química poderá servir de base a uma nova empresa de defensivos agrícolas. Outro grupo especialista em síntese orgânica quiral poderá promover a evolução de uma indústria farmacêutica interessada na obtenção de um farmoquímico enantiomericamente puro. Etc, etc.

É importante ressaltar que o domínio de uma disciplina estabelece apenas o potencial para o que pode ser obtido. Somente a eficácia de uma organização poderá converter esse potencial em resultados. E isto está relacionado à capacidade de integração e à capacidade empreendedora.

Desta maneira o País integrará de forma autosustentada aquilo que tem de mais valioso: a sua gente com sua vocação inesgotável por um futuro melhor. A elite intelectual brasileira, terá a oportunidade histórica de participar na formação e desenvolvimento de uma indústria brasileira intensiva em conhecimento. Surgirá assim um novo tipo de organização que deverá integrar a ciência pura com a aplicada. O desenvolvimento sistêmico resgatará a dimensão humana, esquecida na teoria econômica. $\mathrm{O}$ Governo e a indústria aprenderão que a ciência básica e a metodologia científica, são essenciais para a criação de futuro. Terá nascido assim a indústria química brasileira do século XXI. Um novo instrumento de desenvolvimento social. 